\title{
ROLE OF INTERLEUKIN-6 AND PROCALCITONIN AS INFLAMMATORY BIOMARKERS IN EVALUATING COVID-19 DISEASE SEVERITY ON HRCT CHEST- AN EXPERIENCE AT CMH QUETTA
}

\author{
Azeema Ahmed, Zeeshan Ayub, Farah Afzal, Saima Bashir, Hamid Iqbal, Khurram Haq Nawaz \\ Combined Military Hospital Quetta/National University of Medical Sciences (NUMS) Pakistan
}

\begin{abstract}
Objective: To explore the relation of Interleukin-6 and Procalcitonin with COVID-19 severity on high resolution computerized tomogram (HRCT) chest.

Study Design: Randomized Control Trial (NCT04945811).

Place and Duration of study: Pathology Department, Combined Military Hospital Quetta, from April 2020 to May 2021.

Methodology: Serum Interleukin-6 and Procalcitonin of 100 consenting COVID-19 positive patients from April 2020 to May 2021 were assessed at Pathology department Combined Military Hospital Quetta and their levels were correlated with severity of lung involvement on HRCT Chest

Results: Serum Interlukin-6 levels were significantly raised in 97 patients with mean levels of $20.43 \pm 19.66$ (pg/ml). Serum procalcitonin levels were also significantly raised in 95 patients with mean levels of $0.43 \pm 0.24(\mathrm{ng} / \mathrm{ml})$.

Conclusion: Interlukin-6 and procalcitonin are important biomarkers for diagnosis and predicting severity of COVID-19 pneumonia.
\end{abstract}

Keywords: COVID-19 pneumonia, Interlukin-6, Procalcitonin.

How to Cite This Article: Ahmed A, Ayub Z, Afzal F, Bashir S, Iqbal H, Nawaz KH. Role of Interleukin-6 and Procalcitonin as Inflammatory Biomarkers in Evaluating Covid-19 Disease Severity on HRCT Chest - An Experience at CMH Quetta. Pak Armed Forces Med J 2021; 71(6): 2131-2134. DOI: https://doi.org/10.51253/pafmj.v71i6.6977

This is an Open Access article distributed under the terms of the Creative Commons Attribution License (https://creativecommons.org/licenses/by-nc/4.0/), which permits unrestricted use, distribution, and reproduction in any medium, provided the original work is properly cited.

\section{INTRODUCTION}

Corona Virus Disease-19 (COVID-19) has emerged as the most lethal zoonotic infection in mankind. Since its emergence in 2019, the entire World has seen three unprecedented waves of this disease with a very unpredictable course and future. ${ }^{1}$ Most of the mortality due to COVID-19 is due to pulmonary involvement. Pulmonary involvement manifests as fever, respiratory distress, desaturation and ultimately death, even in large number of treated patients. This pulmonary involvement is termed as COVID-19 pneumonia. $^{2}$

Pulmonary and other system involvement is due to cytokine storm triggered by high ACE2 levels. ${ }^{3}$ Broman et al suggested that blockage of Interlukin-6 and Interlukin-1 by using Tocilizumab and Anakinara respectively improves survivability in severe COVID19 pneumonia. The pathogenesis of COVID-19 pneumonia is attributed to the florid development of cytokine release syndrome (CRS). ${ }^{4}$

Currently pulmonary involvement is detected using costly and invasive High Resolution Computerized Tomogram (HRCT) Chest, with this investigation being the Gold Standard for diagnosing COVID-19

Correspondence: Dr Zeeshan Ayub, Classified ENT Specialist, Combined Military Hospital, Quetta-Pakistan

Received: 30 Jun 2021; revision received: 20 Aug 2021; accepted: 24 Aug 2021 related lung involvement. ${ }^{5}$ Furthermore, with admission of patients of COVID-19 in an Intensive Care setup monitoring of patient is of the utmost importance to patient's health. Monitoring is either in form of HRCT Chest or inflammatory biomarkers specific to COVID-19 infection. Repeated HRCT Chest exposes the patient to undue radiation, ${ }^{6}$ whereas inflammatory biomarkers provide a cheap alternate plan for COVID severity determination. ${ }^{7}$

Monitoring of COVID-19 disease progression is of the utmost importance to delineate patients having florid pulmonary involvement due to cytokine storm. Interlukin-6 and Procalcitonin (markers of cytokine storm) provide a less invasive alternative in pointing towards possible pulmonary involvement and disease progress monitoring in case of pulmonary involvement.

\section{METHODOLOGY}

This randomized control trial (Clinical Trials. gov Identifier: NCT04945811) was carried out to determine the relation between raised serum Interleukin- 6 and serum procalcitonin and HRCT Chest findings in COVID-19 positive patients at departments of Pathology, at Combined Military Hospital Quetta after approval of Institutional Review Board (File No: CMH QTA-IRB/036) from June 2020 to May 2021. 
A sample size of One hundred consenting patients was calculated with Raosoft sample size calculator (power of test $80 \%$ and margin of error $5 \%$ ), with a prevalence of $0.6 \%$ chest involvement as reported by reported by Bernheim et al. in a study population of 3645 new diagnosis per day (for year 2020). ${ }^{8}$ The patients were selected by non-probability consecutive convenience sampling technique.

Inclusion Criteria: COVID-19 positive patients on PCR, with lung involvement as determined on HRCT chest were included.

Exclusion Criteria: Patients with previous known chronic pulmonary disease like asthma were excluded.

One hundred consenting patients admitted to hospital with positive findings on HRCT Chest underwent estimation of serum Interleukin- 6 and serum procalcitonin. Nasopharyngeal swabs of all patients were collected by ENT Specialist and transported to microbiology lab in viral transport media, maintaining the cold chain at 2-8 degree Celsius and processed within 24 hours. All the specimens were processed by using Qiagen Kit (Germany) for real time polymerase chain reaction. Extraction and amplification SARSCoV-2 RNA was carried out as per manufacturer's instructions. Cycle threshold values $<38$ were taken as positive while $>38$ were taken as negative.

Five milliliters of venous blood samples were drawn under aseptic conditions and serum Interlukin6 levels was measured on COBAS-e 411 Immunoassay analyzer using electro chemiluminescence methodology using Roche Interlukin-6 kit. Raised levels of serum Interlukin-6 were taken as $>7$ pico gram $/$ milliliter $(\mathrm{pg} / \mathrm{ml})$. Serum procalcitonin was also measured by similar methodology using Roche procalcitonin kit. Raised levels of serum procalcitonin were taken as $>0.15$ nano gram/milliliter $(\mathrm{ng} / \mathrm{ml})$. HRCT Chest of the patients was done on 64 slice Toshiba scanner without using contrast. Slice thickness was kept at 1 millimeter and slice interval was 5 millimeter. Average acquisition time was 5-10 seconds.

All the scans were analyzed by the same consultant radiologist first for typical COVID-19 pneumonia having ground glass opacities delineated by the RSNA Consensus statement. Following the above mentioned protocol a score was assigned to each HRCT depending on Lobar involvement (total 5 lobes $=3$ right sided lobes +2 Left sided lobes). Each lobe was given a score from $1-5$ ( $1=<5 \%$ involvement, $2=5-25 \%$ involvement, $3=26-49 \%$ involvement, $4=50-75 \%$ involvement, and $5=$ $>75 \%$ involvement). ${ }^{9}$ Thus total score ranged from a minimum of 5 to maximum of 25. COVID-19 pneumonia was categorized on HRCT chest as Mild with total score 7 or less, moderate with score from $8-17$, and severe with score more than. ${ }^{18}$

Statistical analysis was carried out on Statistical Package for the Social Sciences (SPSS) version 23. Oneway ANOVA test was used to test the significance of serum Interlukin-6 and procalcitonin levels against HRCT Chest severity scores. The $p$-value of $\leq 0.05$ was considered statistically significant.

\section{RESULTS}

A total of 100 adult patients volunteered for the study. Age varied from 38-71 years with mean age $59.20+8.60$ years. Out of total 63 were male and 37 were females. Among the 100 patients of this study, HRCT Chest findings placed 58 patients into mild, 31 in moderate and 11 in severe group.

Serum Interlukin-6 levels were raised in 97 patients with mean levels of $20.43+19.66(\mathrm{pg} / \mathrm{ml})$ in the study population of 100 patients. Mean serum Interlukin- 6 levels in mild, moderate and severe groups were $9.48+1.56,22.73 \pm 2.08$ and $71.67 \pm 14.17$ respectively $p<0.001$ as shown in Table-I. Inter group comparison showed significant difference in serum Interlukin levels within the chest severity groups as shown in Table-II. All patients with normal serum Interlukin-6 and serum procalcitonin levels had mild findings on HRCT Chest.

Table-I: Statistical analysis for chest severity grading.

\begin{tabular}{l|c|c|c|c}
\hline Parameters & $\begin{array}{c}\text { Mild } \\
\text { Group } \\
(\mathbf{n = 5 8 )}\end{array}$ & $\begin{array}{c}\text { Moderate } \\
\text { Group } \\
(\mathbf{n = 3 1 )}\end{array}$ & $\begin{array}{c}\text { Severe } \\
\text { Group } \\
(\mathbf{n = 1 1})\end{array}$ & $\begin{array}{c}p \text { - } \\
\text { value }\end{array}$ \\
\hline Serum Inter- & $9.48 \pm$ & $22.73 \pm$ & $71.67 \pm$ & $<0.001$ \\
lukin-6 (pg/ml) & 1.56 & 2.08 & 14.17 & \\
\hline Serum Pro- & $0.25 \pm$ & $0.58 \pm$ & $0.94 \pm$ & $<0.001$ \\
calcitonin $(\mathrm{ng} / \mathrm{ml})$ & 0.07 & 0.06 & 0.03 & \\
\hline
\end{tabular}

Table-II: Inter-group comparison (Post Hoc analysis).

\begin{tabular}{l|c|c|c}
\hline $\begin{array}{l}\text { Group } \\
\text { Comparison }\end{array}$ & $\begin{array}{c}\text { Mil Group } \\
\text { Vs. } \\
\text { Moderate } \\
\text { Group-2 }\end{array}$ & $\begin{array}{c}\text { Moderate } \\
\text { Group Vs. } \\
\text { Severe } \\
\text { Group-3 }\end{array}$ & $\begin{array}{c}\text { Mild } \\
\text { Group Vs. } \\
\text { Severe } \\
\text { Group }\end{array}$ \\
\hline $\begin{array}{l}\text { Serum Inter- } \\
\text { lukin-6 (pg/ml) }\end{array}$ & $<0.001$ & $<0.001$ & $<0.001$ \\
\hline $\begin{array}{l}\text { Serum Procal- } \\
\text { citonin }(\mathrm{ng} / \mathrm{ml})\end{array}$ & $<0.001$ & $<0.001$ & $<0.001$ \\
\hline
\end{tabular}

\section{DISCUSSION}

Results of our study showed increasing levels of serum Interlukin-6 and procalcitonin with increasing lung involvement on HRCT chest in COVID-19 patients. The results show that both these biomarkers 
of cytokine storm can be used to monitory the course of COVID-19 severity in patients.

Borman et al, in a limited study of 27 patients found that not only was Interlukin-6 increased in patients of COVID-19 pneumonia but the levels of the biomarker raised significantly with increasing severity of the disease. ${ }^{4}$

A meta-analysis by Elshazli of nearly 2000 cases, summarized the importance of Interlukin- 6 as a diagnostic and prognostic biomarker of cytokine storm in COVID-19 pneumonia. A real benefit was shown in disease course by blocking interlukins in early stages of COVID-19 pneumonia. Procalcitonin showed an overwhelming role as a prognostic marker of the disease severity monitoring. ${ }^{10}$

Figliozzi et al, in a meta-analysis of 49 studies comprising of a study population of 2021 patients found that adverse outcome of COVID-19 pneumonia was associated with higher than normal serum procalcitonin levels in 2730 patients. While higher procalcitn in levels were not a predictor of mortality it did help in monitoring the disease progression. ${ }^{11}$ A systematic review by Izcovich et al, of 207 studies comprising of 75607 patients determined poor prognosis for patients suffering from COVID-19 pneumonia with raised levels of serum Interlukin- 6 and serum procalcitonin. ${ }^{12}$

A retrospective cohort study of 140 patients conducted by Liu explored serum Interlukin- 6 and serum Procalcitonin as predictor of moderate and severe COVID-19 pneumonia. They concluded that these two biomarkers were significantly raised in severe COVID-19 pneumonia and disease progression could be monitored by the serum levels of Interlukin- 6 and Procalcitonin. ${ }^{13}$

Marin et al, in a literature review elaborated the use of biomarkers as risk stratification for early identification of pro inflammatory cytokines i.e., Interlukin6. With early identification of rise in serum Interlukin-6 an aggressive response helps to avoid cytokine storm and potentially avoid severe complications. ${ }^{14}$

Cytokine storm is a term coined first nearly 27 years ago to describe a cytokine mediated adverse $T$ cell response seen with chimeric antigen receptor therapy. Since then a new term for this response has been brought in literature i.e., cytokine response syndrome (CRS). The exact definition of cytokine response syndrome is not yet identified, partly due to the fact that cytokines are both helpful in controlling infection and some do promote abnormal host reactions leading to pulmonary adverse outcome. The other reason is that some cytokines are immune enhancing e.g., Interlukin6 and others like Interlukin-1 have an immunosuppressant role. The interdependence of these mediators further complicates the understanding of their role in cytokine response syndrome. ${ }^{15}$

The speed of cytokine response syndrome onset may vary as does the duration but nearly all patients have common late stage manifestations like raised core temperature, weakness, loss of appetite, arthralgia's, body aches, diarrhea and psychiatric findings. These features are a manifestation of direct tissue damage caused by excess cytokines and abnormal immune mediated cellular response. Untreated patients thereon progress rapidly to disseminated intravascular coagulation, hypovolemia, dyspnea, shock and rapidly lead to desaturation and acute respiratory distress syndrome. Apart from pulmonary system the cytokine response syndrome leads to multi organ failure like cardiomyopathy, acute liver failure and acute renal failure. ${ }^{16}$

A systematic approach must be followed for management of patients suspected of cytokine response syndrome i.e., firstly correctly identifying patients by excluding other causes that mimic cytokine response syndrome. ${ }^{17}$ Secondly determining the severity of disease and thirdly identifying a proper course for treatment and disease monitoring. Detection and serial measurement of pro inflammatory cytokines like Interlukin- 6 helps in early identification of cytokine response syndrome and disease progression monitoring. Interlukin-6 is involved in activation of mast cells, dendritic cells, and macrophages. Degranulation of macrophages is one of the triggers for propagation of cytokine cascade. ${ }^{18}$ Fajgenbaum proposed three criteria for establishing cytokine response syndrome: elevated cytokine (Interleukin-6) levels, systemic inflammatory symptoms and end organ dysfunction. The earlier cytokine response syndrome is identified the earlier appropriate therapy can be started. ${ }^{19}$

\section{CONCLUSION}

Serum Interlukin- 6 and serum procalcitonin are essential in diagnosing cytokine response syndrome and also have a major role in detecting severity of COVID-19 pneumonia due to cytokine response syndrome.

\section{Conflict of Interest: None.}

\section{Authors' Contribution}

AA: Conception design, ZA: Conception design, FA: Data analysis, SB: Data analysis, HI: Substantial, KHN: Substantial. 


\section{REFERENCES}

1. Terpos E, Ntanasis-Stathopoulos I, Elalamy I, Kastritis E, Sergentanis TN, Politou M, et al. Hematological findings and complications of COVID-19. Am J Hematol 2020; 95(7): 834-847.

2. Tjendra Y, Al-Mana AF, Espejo AP, Akgun Y, Millan NC, Gomez-Fernandez $C$, et al. Predicting disease severity and outcome in COVID-19 patients: a review of multiple biomarkers. Arch Pathol Lab Med 2020; 144(12): 1465-1474.

3. Wang J, Jiang M, Chen X, Montaner LJ. Cytokine storm and leukocyte changes in mild versus severe SARS-CoV-2 infection: Review of 3939 COVID-19 patients in China and emerging pathogenesis and therapy concepts. J Leukoc Biol 2020; 108(1): 17-41.

4. Broman N, Rantasärkkä K, Feuth T, Valtonen M, Waris M, Hohenthal U, et al. IL-6 and other biomarkers as predictors of severity in COVID-19. Ann Med 2021; 53(1): 410-412.

5. Lee DW, Santomasso BD, Locke FL, Ghobadi A, Turtle CJ, Brundo JN, et al. ASTCT consensus grading for cytokine release syndrome and neurologic toxicity associated with immune effector cells. Bio Blood Marrow Transplant 2019; 25(1): 625-38.

6. Hu B, Huang S, Yin L. The cytokine storm and COVID-19. J Med Virol 2021; 93(1): 250-256.

7. Pan F, Ye T, Sun P, Gui S, Liang B, Li L, et al. Time Course of Lung Changes at Chest $\mathrm{CT}$ during Recovery from Coronavirus Disease 2019 (COVID-19). Radiol 2020; 295(3): 715-721.

8. Bernheim A, Mei X, Huang M, Yang Y, Fayad ZA, Zhang N, et al. Chest CT Findings in coronavirus disease-19 (COVID-19): relationship to duration of infection. Radiol 2020; 295(3): 200463.

9. Simpson S, Kay FU, Abbara S, Bhalla S, Chung JH, Chung M, et al. Radiological society of north america expert consensus statement on reporting chest CT findings related to COVID-19. endorsed by the society of thoracic radiology, the american college of radiology, and RSNA - secondary publication. J Thoracic Imag 2020; 35(4): 219-227.
10. Elshazli RM, Toraih EA, Elgaml A, El-Mowafy M, El-Mesery M, Amin $\mathrm{MN}$, et al. Diagnostic and prognostic value of hematological and immunological markers in COVID-19 infection: A meta-analysis of 6320 patients. PLoS One 2020; 15(8): e0238160.

11. Figliozzi S, Masci PG, Ahmadi N, Tondi L, Koutli E, Aimo A, et al. Predictors of adverse prognosis in COVID-19: A systematic review and meta-analysis. Eur J Clin Invest 2020; 50(10): e13362.

12. Izcovich A, Ragusa MA, Tortosa F, Lavena-Marzio MA, Agnoletti C, Bengolea A, et al. Prognostic factors for severity and mortality in patients infected with COVID-19: A systematic review. PLoS One 2020; 15(11): e0241955.

13. Liu F, Li L, Xu M, Wu J, Luo D, Zhu Y, et al. Prognostic value of interleukin-6, C-reactive protein, and procalcitonin in patients with COVID-19. J Clin Virol 2020; 127(1): 104370.

14. Gallo Marin B, Aghagoli G, Lavine K, Yang L, Siff EJ, Chiang SS, et al. Predictors of COVID-19 severity: A literature review. Rev Med Virol 2021; 31(1): 1-10.

15. Saeed GA, Gaba W, Shah A, Al Helali AA, Raidullah E, Al Ali, et al. Correlation between Chest CT Severity Scores and the Clinical Parameters of Adult Patients with COVID-19 Pneumonia. Radiol Res Pract 2021; 2021(1): 6697677.

16. Tang J, Lin J, Zhang E. Serum IL-6 and procalcitonin are two promising novel biomarkers for eva-luating the severity of COVID19 patients. Medicine (Baltimore) 2021; 100(22): e26131.

17. Tian J, Yuan X, Xiao J, Zhong Q, Yang C, Liu B, et al. Clinical characteristics and risk factors associated with COVID-19 disease severity in patients with cancer in Wuhan, China: a multicentre, retrospective, cohort study. Lancet Oncol 2020; 21(7): 893-903.

18. Copaescu A, Smibert O, Gibson A, Phillips EJ. The role of IL-6 and other mediators in the cytokine storm associated with SARSCoV-2 infection. J Allergy Clin Immunol 2020; 146(3): 518-534.

19. Fajgenbaum DC, June CH. Cytokine Storm. N Engl J Med 2020; 383(23): 2255-2273. 